\title{
EL DESARROLLO DE LAS PAUTAS EMANADAS DE UN DOCUMENTO CURRICULAR EN DOS LIBROS DE TEXTO
}

Silvia Méndez Ancbia

\begin{abstract}
Resumen: En ocasiones el libro de texto sustituye al programa de estudios y conforma el verdadero curriculo con que trabajan profesores y alumnos. En este articulo se estudia la forma como dos libros de texto desarrollan las pautas emanadas del programa de estudios de Español para noveno año del Ministerio de Educación Pública de Costa Rica, específicamente en el tema del ensayo literario. Se definen las orientaciones didáctica, temática y teórico-literaria del documento curricular. Se aplica una guia de análisis para determinar el tratamiento que cada texto le da al tema, y establecer su relación con el programa de estudios. Se concluye que de un mismo documento curricular pueden desprenderse desarrollos diferentes en el nivel de los libros de texto: 1. Una orientación didáctica pasiva, en Español $9^{\circ}$ año; y activa, en Español 9. 2. Diferente tratamiento del tema del género ensayistico entre ambos textos, que obedece a marcos de referencia distintos, aunque es mâs profundo en Español 9. 3. En ambos libros, un análisis de los ensayos basado en las ideas, con una menor consideración de los criterios programáticos. 4. Orientación teórico-literaria cercana al estructuralismo en Español 9año, y un énfasis en los aspectos sociocríticos en Español 9.
\end{abstract}

\section{INTRODUCCIÓN}

Muchas son las definiciones de "currículo". En este artículo se atiende a una definición más bien estrecha, ligada al "plan de estudios", tal y como lo apunta el Diccionario de la Real Academia. Esta decisión no es arbitraria; todo lo contrario, intenta enfocar la atención hacia un elemento específico del currículo: el programa de estudios, y, especialmente, el programa oficial, del Ministerio de Educación Pública de Costa Rica.

Ahora bien, ¿cuál es el punto de contacto entre ese documento curricular y los libros de texto? Cecilia Dimaté Rodríguez lo ha planteado en términos de una posible sustitución del programa de estudios por el libro de texto, pues este comprende tanto contenidos como actividades que orientan, de una forma específica, el proceso de enseñanza-aprendizaje. Señala lo siguiente:

"...el texto escolar -en muchos casos- es el que realmente conforma el verdadero currículo, y no los programas oficiales de los Ministerios de Educación, no sólo por el manejo que hace de objetivos y contenidos, sino también por sus propuestas de actividades, evaluaciones y estrategias didácticas, entre otras." (Dimaté, 1994, p. 31).

Dada la importancia que, a partir de la cita anterior, se confiere a los libros de texto como posibles sustitutos de los programas oficiales, interesa estudiar, en esta investigación, 
los lineamientos del programa de estudios de Español de noveno año del Ministerio de Educación Pública y su desarrollo en dos libros de texto destinados a ese nivel.

$\mathrm{El}$ problema que enfoca este artículo es, entonces, el siguiente: ¿Cómo se desarrollan, en los libros de texto Español 9a año y Español 9, las pautas emanadas del programa de estudios de Español de noveno año, del Ministerio de Educación Pública de Costa Rica, específicamente en el tema del ensayo literario?

\section{PREMISAS CONCEPTUALES}

Dos elementos de índole teórica son fundamentales para el análisis propuesto. El primero, señalar la orientación didáctica, temática y teórico-literaria que sustenta el programa oficial de Español de noveno año del Ministerio de Educación Pública. Y el segundo, comentar en qué consisten los libros de texto estudiados.

Seguidamente, se expone un resumen de los principales elementos que aparecen en el programa de estudios.

\subsection{Programa de estudios de español de noveno año}

Forma parte de un documento curricular titulado "Programa de estudios de español tercer ciclo", del Ministerio de Educación Pública. Fue publicado en 1995, y se mantiene vigente hasta la fecha.

Se estructura de la siguiente forma: una parte general, que contiene la justificación, el enfoque general para la enseñanza del espanol, orientaciones para la mediación docente, sugerencias para la evaluación y los objetivos del tercer ciclo; luego vienen tres secciones específicas, correspondientes a los niveles que componen dicho ciclo, para cada uno de los cuales se señalan los objetivos, principios elementales de la lengua y la literatura, escucha, expresión oral, lectura, expresión escrita, otros componentes que deben integrarse a las habilidades comunicativas, así como el lis- tado de los textos literarios de lectura obligatoria para el nivel.

Dada la concreción de este trabajo, la exposición de los diversos puntos del programa se hará atendiendo a tres aspectos: orientación didáctica, orientación temática y orientación teórico-literaria de aquellos contenidos del programa de estudios que se relacionan con el tema "El ensayo".

\subsubsection{Orientación didáctica}

Según el programa de estudios, un enfoque general de la enseñanza del español debe contemplar un modelo de producción textual cuyos componentes son tres: el motivacional, el conceptual y el lingüístico; este último, a su vez, se divide en seis subcomponentes (el pragmático, el discursivo, el semántico, el léxico, el morfosintáctico y el notacional y locutivo). Dentro de este enfoque, la lectura literaria se considera parte de un proceso de producción de textos en el cual todos esos componentes se integran en función del lenguaje literario, es decir, que su significado va más allá de lo denotativo.

Una vez definidos estos componentes, el documento en estudio brinda una serie de orientaciones para la mediación docente. La principal consiste en señalar tanto la importancia de los contenidos seleccionados como el procedimiento mediante el cual se incorporan dichos temas a la experiencia didáctica; con tal fin, se recomienda que la metodología empleada sea activa y que promueva el aprendizaje significativo de los alumnos.

\footnotetext{
"Para esto, la enseñanza de la lengua materna debe fundamentarse no sólo en una cuidadosa selección de los contenidos, sino, también, en una metodología activa, participativa y promotora del aprendizaje significativo de los educandos, de tal manera que se pueda alcanzar el perfil propuesto." (Costa Rica, MEP, 1995, p. 7).
}

\subsubsection{Orientación temática}

Entre los objetivos del programa de estudios de Español para noveno año, interesa destacar los siguientes, ya que se relacionan con los textos literarios y con el género ensayístico: 
"2. Reconoce la literatura como una práctica social, como una forma ideológica y como una institución.

(..)

5. Comprende el género literario (ensayo) y los movimientos literarios (Naturalismo y Modernismo) como funciones convencionales del lenguaje y como relaciones particulares con el mundo, que sirven de regulación o de expectativa para guiar al lector en el encuentro con el texto.

6. Fortalece la comprensión del género y del movimiento literarios al ampliar lo ya estudiado (épica, lírica y drama; Romanticismo y Realismo).

(..)

10. Identifica el predominio de las diversas categorias constitutivas en cada uno de los géneros, con el fin de obtener una visión global de las regulaciones que han orientado la lectura y la escritura de lo literario." (Costa Rica, MEP, 1995, p. 36).

En cuanto a los contenidos propiamente tales, para efectos de este trabajo, se destacan los siguientes:

"La literatura como práctica social, como forma ideológica y como institución.

El género literario (ensayo) y los movimientos literarios ( $\mathrm{Na}$ turalismo y Modernismo) como funciones convencionales del lenguaje y como relaciones particulares con el mundo. (...)

Los géneros y las regulaciones de la lectura y escritura de lo literario." (Costa Rica, MEP, 1995, p. 36).

En este primer grupo, los contenidos son bastante generales. Sirven como punto de referencia acerca de las distintas funciones de la literatura. Asimismo, contemplan la definición de categorías básicas, como la de género literario.

Otro segundo grupo de contenidos giran en torno al análisis de los textos literarios propuestos como de lectura obligatoria. En este caso, se trata de los ensayos " $¿ Q u e ́$ hora es...?", de Yolanda Oreamuno, y "La isla que somos", de Isaac Felipe Azofeifa. A continuación, se transcriben tales contenidos:

\section{"El Ensayo:}

Análisis de algunos elementos:

Los registros del habla.

El hablante en primera persona como recurso coloquial. El código apreciativo.

Relaciones entre el emisor y el receptor.

Relaciones de ¿Qué hora es? y de La isla que somos con el contexto sociocultural y con el género literario."

(Costa Rica, MEP, 1995, p. 40)

\subsubsection{Orientación teórico-literaria}

El programa de estudios no hace ninguna referencia explícita a la orientación teórico-literaria que lo sustenta. No obstante, por la terminología empleada, puede evidenciarse una mezcla de postulados teóricos correspondientes a la escuela sociocrítica, con un marco de análisis de cada texto literario que resulta cercano al estructuralismo. El porqué de esta afirmación se aclara en los párrafos siguientes.

Muchas de las definiciones que el programa apunta se han tomado del Diccionario de términos asociados en teoría literaria, de (María Amoretti, 1992); tales definiciones son las siguientes: la literatura como práctica social, la literatura como forma ideológica, la literatura como institución (Amoretti, 1992, pp. 77-78), también las nociones de género y movimiento literarios como funciones convencionales del lenguaje y formas de relación particular con el mundo (Amoretti, 1992, p. 56). Ahora bien, cuando la autora introduce su Diccionario lo presenta como un aporte bibliográfico hecho desde una perspectiva sociocrítica:

"La idea de un diccionario nace, por una parte, de las extraordinarias dificultades bibliográficas que enfrenta esta materia en la lengua española, y por otra, de la naturaleza misma de una disciplina que, como la sociocrítica, se inspira en un nuevo concepto de humanismo..." (Amoretti, 1992, pp. 9-10).

Por tanto, los términos extraídos de esa fuente y anotados en el documento curricular se orientan por tal corriente teórico-literaria.

Otros criterios que aparecen en el programa, específicamente algunos de los que se mencionan como elementos para el análisis de los ensayos propuestos, tienen una vinculación más cercana con otra posición de la teoría literaria: el estructuralismo. Así, las nociones de registros del habla y código apreciativo aparecen en la Poética, de (Tzvetan Todorov, 1975), texto que podría considerarse el manifiesto estructuralista por excelencia. Otro elemento, el de las relaciones entre emisor y receptor, resulta tan amplio que podría 
leerse casi de cualquier modo, pero también dentro de la Poética todoroviana, de manera que el contexto lo promueve.

Queda definida, asi, la confluencia de criterios sociocríticos y estructuralistas en la aproximación de lectura literaria que propone el programa de estudios de español del Ministerio de Educación Pública, en lo que a noveno año se refiere.

\subsection{Los libros de texto analizados}

\subsubsection{Español $9^{\circ}$ año}

El libro Español 9a año (Varela y Sandino, 1997) desarrolla los contenidos correspondientes a la asignatura de Español en el noveno año. Sus autores son los profesores Wálter Sandino Angulo y Marubeni Varela Ba:boza. Si bien este libro no constituye un texto oficial del Ministerio de Educación Pública, su uso se halla muy difundido en ciertas regiones del país.

\subsubsection{El libro de texto Español 9}

El libro de texto Español 9 (Víquez, Rojas y Rojas, 1996) forma parte de los materiales educativos de la serie "Hacia el siglo XXI", cuya elaboración se desarrolló durante la administración Figueres Olsen (1994-1998) y cuya vigencia se ha mantenido durante la presente administración. Esta serie fue redactada por un cuerpo de docentes de la Universidad de Costa Rica, y su edición estuvo a cargo de la Editorial de esa casa de estudios. Constituyen textos oficiales del Ministerio de Educación Pública costarricense.

El material en cuestión se destina a la enseñanza de la lengua materna en el noveno año de la educación general básica. Sus autores son Alí Víquez, Lilliam Rojas y Marta Rojas.

Por la similitud en los títulos de los dos libros analizados, se ha decidido referirse a este acompañándolo del título de la serie a la que pertenece: "Hacia el siglo XXI".

\section{METODOLOGÍA}

Para el estudio de los libros de texto Español 9a año y Español 9 (serie "Hacia el siglo XXI"), y su confrontación con el programa de estudios del Ministerio de Educación Pública, se determinó una unidad de análisis y se creó un instrumento que proveyera de cierta sistematicidad al análisis realizado. Seguidamente, se explica en qué consisten ambos elementos.

\subsection{Unidad de análisis}

Dada la extensión de los libros seleccionados, se escogió una unidad de ellos, con el fin de realizar, a partir de esta, el análisis respectivo. En ambos casos se trata de la unidad titulada "El ensayo", la cual desarrolla los contenidos del programa de estudios correspondientes a ese tema. En el libro Espanol $9^{\circ}$ año, esta temática aparece expuesta en las páginas 273 a 291; mientras que en el libro Español 9 (serie "Hacia el siglo XXI") este contenido se desarrolla en las páginas 224 a 233 .

\subsection{Instrumento y definición de categorias}

El estudio de las unidades escogidas se hizo mediante una "Guía de análisis" elaborada para efectos de este trabajo. En ella se consideraron los distintos elementos mencionados en el programa de estudios de Español de noveno año del Ministerio de Educación Pública, tanto en términos generales (la orientación didáctica y teórico-literaria) como en términos más específicos (la orientación temática), los cuales se confrontaron con el tratamiento del tema "El ensayo" en cada uno de los libros de texto. (En el anexo se incluye la "Guía de análisis del desarrollo del programa de estudios de Español de noveno año en dos libros de texto").

A continuación se presenta una definición de las categorías incluidas en ese instrumento. Por tratarse de un campo en el cual 
existe diversidad de aproximaciones teóricas, estas premisas conceptuales se basan, preferentemente, en lo que plantea el programa de estudios del Ministerio de Educación Pública. Śin embargo, como dicho programa no hace explícita su posición respecto de algunas de esas categorías, se ha recurrido a otro tipo de fuentes, sobre todo de procedencia ministerial, como algunos materiales elaborados por funcionarios del Kiosco de Información. En otros casos, se ha consultado el Diccionario de términos asociados en teoria literaria, de (María Amoretti, 1992).

\subsubsection{Categorias relacionadas con la orientación didáctica}

Metodología activa: En el programa de estudios de español del Ministerio de Educación Pública, se asocia la metodología activa con la promoción del aprendizaje significativo. Para su aplicación, el documento brinda recomendaciones como las siguientes: crear la necesidad y el placer de leer, presentando el contacto con el texto de maneras diferentes, en las cuales predomine un afán lúdico, que invite a los estudiantes a explotar los sentidos de los textos; realizar actividades que promuevan la imaginación, el juicio crítico y la actitud creadora, a la vez que permitan efectuar un distanciamiento de la realidad para objetivarla, jerarquizarla y cuestionarla; construir el significado con base en los textos y en su experiencia anterior, es decir, con el aporte de sus conocimientos, valores y creencias.

Metodologia "pasiva": Por contraste con la anterior, se podría considerar "pasiva" una metodología que no cumpla con estos lineamientos, es decir, una que se acerque más a un modelo autoritario, vertical y unidireccional. En ella predominaria la directividad, que enfatiza en los contenidos (seleccionados por la instancia docente) y en unos objetivos predeterminados.

\subsubsection{Categorias relativas a la orientación temática}

\subsubsection{En términos generales}

La literatura como práctica social: Se concibe la literatura como un proceso de producción material que responde a las prácticas de una sociedad específica. Ello en contraposición a una noción idealista, que considera la creación literaria como el resultado de la "inspiración" de un individuo en particular. (Amoretti, 1992).

La literatura como forma ideológica: Este criterio alude a la imbricación y articulación interna entre historia y literatura. (Amoretti, 1992) señala lo siguiente: "La literatura es una forma ideológica que se realiza a través de ciertos AIE, bajo la forma de prácticas determinadas (la práctica lingüística sería una de ellas" (p. 78).

La literatura como institución: Sus manifestaciones más externas son las asociaciones de autores; los mecanismos de reconocimiento; actividades tales como los simposios y congresos; el mercado de edición; los códigos de legitimación o de legitimidad. Esas son solo manifestaciones externas, ya que el concepto se refiere a la literatura como un aparato con una función reguladora y simbólica. (Amoretti, 1992).

El género ensayístico como una función convencional del lenguaje y como una forma de relación particular con el mundo, que sirve de regulación o de expectativa para guiar al lector en el encuentro con el texto: Esta concepción del ensayo se basa en el criterio de que las distinciones genéricas son producto de un acuerdo de la institución literaria, acuerdo que, en tanto tal, es siempre relativo y variable según las condiciones específicas de producción de la literatura. De este acuerdo se desprende una especie de "contrato de lectura", según el cual el lector, al aproximarse al texto, llevará consigo una serie de expectativas que orientarán su labor de construcción de significados.

El género ensayístico como ampliación de los géneros literarios estudiados en niveles 
anteriores (épica, lírica y drama): Se refiere a la noción de género literario tal como se planteó en el párrafo anterior. En otras palabras, alude a la ampliación del concepto como "función convencional del lenguaje y como una forma particular de relación con el mundo", cuyo punto de partida se situó en el estudio de la épica y la lírica (iniciado en sétimo año) y fue seguido por el drama (en octavo año).

Categorias constitutivas del género ensayistico, como parte de las regulaciones que ban orientado la lectura y la escritura de lo literario: El género ensayístico se presenta como una noción relacionada con una serie de caracteristicas que determinan la forma en que el lector se acerca al texto. En este punto, respecto del cual existe diversidad de criterios, el documento curricular no explicita a cuáles categorías se refiere.

\subsubsection{En términos especificos (con base en cada uno de los ensayos estudiados)}

Registros del babla: Según (Murillo, 1996), los registros son aquellas variedades lingüísticas que aparecen determinadas por la situación. Incluye aquí diversos tonos, a saber, serio, humorístico, irónico, etc. También considera los tipos de lenguaje empleados por el hablante: culto, popular, regional, especializado, común, poético, entre otros.

Función del bablante en primera persona como recurso coloquial: El empleo de la primera persona ("yo") por parte del hablante del texto, busca conferirle al ensayo un matiz coloquial, como si se tratara de establecer una conversación con el receptor, a fin de acercarlo al texto. (Murillo, 1996).

Código apreciativo: Esta categoría contempla el criterio valorativo del hablante ante el mundo mostrado, por ejemplo, sus ideas ante la vida, su visión de mundo, su código moral, entre otros. (Murillo, 1996).

Relaciones entre el emisor y el receptor: Se refiere a los recursos empleados por el hablante para establecer una mejor relación con el lector. (Murillo, 1996) cita, entre estos recursos, el uso del lenguaje directo, la interpelación, así como aquellos mecanismos por medio de los cuales se facilita, al lector, la comprensión de las ideas expuestas (comparaciones, síntesis...).

Contexto sociocultural: Este elemento de análisis puede ser interpretado en términos bastante amplios, como uno de los elementos de la comunicación literaria (autor, lector, texto y contexto). También podría referirse a las condiciones de posibilidad del texto literario.

\subsubsection{Categorias relacionadas con la orientación teórico-literaria}

Como ya se señaló en el apartado 2.1.3, se consideran de orientación sociocritica los elementos siguientes: la literatura como práctica social, como forma ideológica y como institución, lo mismo que las nociones de género y movimiento literarios como funciones convencionales del lenguaje y formas de relación particular con el mundo; en términos generales, podría hablarse de aquellas categorías relacionadas con el señalamiento de la función ideológica de la literatura y su relación con el contexto social. Por su parte, como representativos de la corriente estructuralista, se consideran elementos tales como los registros del habla, el código apreciativo y las relaciones emisor-receptor, es decir, los elementos específicos que el programa cita para el análisis de los textos ensayísticos.

\section{ANÁIISIS DE RESULTADOS}

A continuación se presenta el análisis comparativo entre la propuesta programática del Ministerio de Educación Pública para la asignatura de Español de noveno año (específicamente en lo relativo al tema del ensayo literario) y lo desarrollado en los libros de texto Español 9a año y Español 9 (serie "Hacia el siglo XXI"). Esta comparación gira en 
torno a tres orientaciones: la didáctica, la temática y la teórico-literaria.

Asimismo, por tratarse de dos libros de texto, simultáneamente se hará la comparación entre ambos.

\subsection{Orientación didáctica}

En el libro Español $9^{\circ}$ año la sección dedicada al ensayo se compone de dos unidades: una para el texto "¿Qué hora es...?", de Yolanda Oreamuno, y la otra para "La isla que somos", de Isaac Felipe Azofeifa; se trata de los dos textos que señala el programa de estudios del Ministerio de Educación Pública como lecturas obligatorias para este nivel.

Ambas unidades poseen la misma estructura. Primero, se transcribe, a manera de objetivo, el contenido relacionado con el análisis específico de los textos ensayísticos, en forma muy similar a como aparece en el pro- grama de estudios. Así, en la página 273, inmediatamente después el título dice:

\section{"Objetivo:}

Reconocer los diferentes elementos que conforman el género ensayístico.

*Los registros del habla.

"El hablante en primera persona como recurso coloquial.

"El código apreciativo.

*Relaciones entre el emisor y el receptor.

"Relaciones del texto con el contexto sociocultural, con el género y con el movimiento literario." (Varela y Sandino, 1997, p.273).

Luego del objetivo, se reproduce el texto literario $\mathrm{y}$, a continuación de este, se plantean las ideas claves del texto. Por último, vienen una serie de actividades, las cuales son el producto de la transformación del objetivo inicial en varios ejercicios. En el siguiente cuadro se comparan las actividades del libro con el contenido que plantea el programa oficial, para ejemplificar lo anteriormente apuntado.

\section{PROGRAMA DEL MINISTERIO DE EDUCACIÓN PÚBLICA DE COSTA RICA}

\section{LIBRO ESPAÑOL $9^{\circ}$ AÑo, DE VARELA Y SANDINO} (1997)
Relaciones de ¿Qué hora es? y de La isla que somos con el contexto sociocultural y con el género literario.

Fortalece la comprensión del género y del movimiento literarios al ampliar lo ya estudiado (épica, lírica y drama; romanticismo y realismo).

Los registros del habla.

El hablante en primera persona como recurso coloquial.

El código apreciativo.
"Anoto el género literario y sus características." (p. 280). "Investigo el contexto sociocultural y lo relaciono con el ensayo." (p. 280).

"Menciono el movimiento literario. Ejemplifico sus características." (p. 280).

"Explico los registros del habla (variantes lingüísticas). Doy ejemplos. Observo si el hablante utiliza la primera persona como recurso coloquial." (p. 281).

"Comento la posición del yo discursivo ante el mundo mostrado (=código apreciativo)." (p. 281).

"Establezco la relación entre emisor y receptor." (p. 281).
Con base en esta descripción de las unidades, puede decirse que la metodología empleada no es activa.

En primer lugar, ambas unidades aparecen estructuradas de la misma forma. Esta disposición contradice la indicación progra- mática según la cual para lograr un aprendizaje significativo es necesario que se presenten, al estudiante, diversas formas de entrar en contacto con los textos literarios.

Además, cada unidad se maneja en términos bastante tradicionales: un objetivo, un 
análisis y unos ejercicios. En este sentido, el libro sigue una pauta muy directiva: el estudiante responde a una estructura definida de antemano, lo que le impide participar de la construcción del significado del texto.

Tomando como base las recomendaciones programáticas en torno a la promoción de un aprendizaje significativo, puede afirmarse que la forma de aproximación al texto literario que se da en el libro Español $9^{\circ}$ año no promueve ese tipo de aprendizaje. Por último, debe observarse que, aunque los ejercicios se plantean en forma bastante abierta (es decir, que no limitan al estudiante a reproducir el análisis expuesto en la unidad), no se les proporciona antes una guía para el estudio de tales categorías, por lo cual podría resultarles difícil la realización de dichas actividades.

Antes de pasar al siguiente libro de texto, conviene aclarar que, en uno de estos ejercicios, se observa una interpretación errónea del programa, ya que se pretende tomar los ensayos citados como muestras de algún movimiento literario en particular. La actividad del libro de texto Español $9^{\circ}$ año que pide mencionar el movimiento literario y sus características no es del todo pertinente, pues el documento curricular parece referirse al estudio de estos ensayos como una forma de ampliar los conocimientos en cuanto a los géneros ya estudiados en sétimo y octavo años (épica, lírica y drama). La ampliación en cuanto a movimientos literarios viene dada, en este nivel, por medio de otros textos, principalmente narrativos: "La compuerta número doce" y El jaúl (representativos del Naturalismo); o líricos: cuatro poemas de Rubén Darío, uno de Roberto Brenes Mesén y uno de Julián Marchena (representativos del Modernismo).

El libro Español 9, de la serie "Hacia el siglo XXI", también presenta una sección dedicada al ensayo, pero esta no aparece dividida en unidades, sino que se trabaja como un todo, aunque los ensayos analizados ("¿Qué hora es...?" y "La isla que somos") se abordan en forma consecutiva. Al terminar de analizar ca- da ensayo, se plantean ejercicios. Como cierre de la unidad aparecen una serie de "Reflexiones en torno al género ensayístico".

Concordando con la orientación didáctica del programa de estudios del Ministerio de Educación Pública, la metodología empleada en este texto es activa. Se intenta que el aprendizaje resulte significativo para los estudiantes; con tal fin, emplea diferentes recursos. A continuación se dan varios ejemplos.

La forma de presentar cada uno de los ensayos es diferente: para el caso de "¿Qué hora es...?", lo hace mediante una exposición ejemplificada; mientras que, para "La isla que somos", utiliza una guía de lectura dirigida al estudiante. Ello se ajusta a la directriz programática que señala la necesidad de que el joven se relacione de diversas maneras con los textos literarios.

El libro de la serie "Hacia el siglo XXI" toma en cuenta los conocimientos previos de los alumnos. Así, la unidad inicia de la siguiente forma: "Se estudiará ahora un género literario que no se ha leído en años anteriores: el ensayo" (Víquez y otros, 1996, p. 224). Con esta anotación, los autores les recuerdan, a los lectores, que ya han estado en contacto con textos pertenecientes a diversos géneros, a la vez que les anuncian la introducción de un género "nuevo" para ellos.

Además, en esta unidad se apela a las posibles impresiones de los estudiantes ante el texto: "¿Qué le pareció este ensayo? ¿Cuáles son sus primeras impresiones sobre el género ensayístico?" (Víquez y otros, 1996, p. 224). Esto resulta significativo en la medida en que incorpora a los estudiantes a partir de sus reacciones iniciales ante el texto; no los limita a una función pasiva, sino que los interpela para crearles la necesidad de leer y de responder ante lo que los textos les dicen.

Al mismo tiempo, se promueve la identificación de los estudiantes con la autora del ensayo, quien lo escribió cuando era una adolescente: "Este es un texto escrito en su primera versión por una adolescente (...) ¡Qué forma de escribir tan buena para alguien tan joven!" (Víquez y otros, 1996, p. 224). Con este 
recurso se está tomando en cuenta la necesidad que tienen los adolescentes de elaborar su identidad a partir de modelos procedentes de diversas instancias culturales.

Por su parte, el componente motivacional de la experiencia, muy propio del aprendizaje significativo, aparece bien desarrollado. Así, se busca fomentar una necesidad comunicativa, la cual se propicia mediante ejercicios planteados como "Temas para la discusión". Estos se orientan, entre otras cosas, a generar criticidad en los estudiantes; véase, a manera de ejemplo, el siguiente:

\begin{abstract}
"Aquí se exponen una serie de propuestas para la formación de la mujer como ser humano. ¿Le parece que estas propuestas sólo son aplicables para la mujer? ¿Acaso no deberían los varones ser formados también para la independencia y la libertad?" (Viquez y otros, 1996, p. 227).
\end{abstract}

Analizado este primer punto, de la orientación didáctica, se encuentran dos diferencias apreciables en cuanto al desarrollo del programa de estudios: la del libro Español $9^{\circ}$ año, que, en un afán por apegarse a los contenidos del programa, deja de lado su propuesta metodológica activa; y la del material de la serie "Hacia el siglo XXI", cuyo desarrollo del programa respeta más la aproximación metodológica activa.

\subsection{Orientación temática}

El análisis del tratamiento de los temas en las unidades correspondientes al género ensayístico, se ha dividido en dos fases. La primera de ellas abarca lo que se refiere propiamente al género ensayístico, es decir, los aspectos más generales. La segunda contempla la presentación específica de cada uno de los textos, a saber, "¿Qué hora es...?" y "La isla que somos".

\subsubsection{En términos generales}

En cuanto a la orientación temática entendida en términos generales, es decir, respecto de aquellos temas relacionados con el género ensayístico propiamente tal, el libro Español $9^{\circ}$ año brinda una introducción a es- ta materia, pero en otra parte del volumen (en la página 104), es decir, tal introducción del género ensayístico no aparece articulada con la unidad que aquí se estudia. En ella se citan cinco características del ensayo: escritura en prosa, variabilidad en su extensión, carácter subjetivo, carácter ancilar y superficialidad en el enfoque de los temas.

Sin embargo, hay un componente de la unidad estudiada que podría mover a confusión a los alumnos. El objetivo de esta -que se reproduce en el apartado 4.1 de este artículo- se enuncia en términos de un reconocimiento de los diferentes elementos que conforman el género ensayístico, y a continuación se citan aquellos que el programa propone como elementos de análisis: registros del habla; hablante en primera persona; código apreciativo; relaciones entre el emisor y el receptor; relaciones del texto con el contexto sociocultural, con el género y el movimiento literarios. Según esta forma de plantear el objetivo de la unidad, podría interpretarse que tales elementos se refieren a las categorías constitutivas del género, lo cual marcaría un evidente conflicto con las características citadas en la página 104.

Del análisis anterior, se desprende que este libro de texto es poco claro en el tratamiento del género ensayístico.

Pasando al otro material estudiado, el de la serie "Hacia el siglo XXI" dedica un apartado, al final de la unidad, para presentar, con base en los textos estudiados, unas reflexiones en torno al género ensayístico. En ellas se plantea el ensayo como una función convencional del lenguaje, además de que se fortalece la comprensión del concepto de género al ampliarlo a lo ya estudiado en niveles anteriores (épica, lírica y drama): "El que un texto se considere 'ensayo' (o novela o cuento o lírica o drama, o simplemente literatura) es algo que se deriva básicamente de un acuerdo" (Víquez y otros, 1996, p. 231).

En este libro no sólo se presenta el predominio de diversas categorias constitutivas del ensayo (literatura de ideas, carencia de ficcionalidad, carácter ideológico, presencia 
de figuras literarias), sino que va más allá porque cuestiona tales rasgos; por ejemplo, cuando se refiere al ensayo como literatura de ideas dice:

"1. La más tradicional de las caracterizaciones habla del ensayo como de literatura de ideas. No obstante, afirmar este rasgo puede ser peligroso pues ¿acaso el resto de la literatura no tiene ideas? ¿Cree usted que, por ejemplo, una novela como El jaúl o un drama como Una aureola para Cristóbal no tienen gran cantidad de ideas?" (Viquez y otros, 1996, p. 231).

De acuerdo con el enfoque de cada libro de texto al presentar el género ensayísti$\mathrm{co}$, puede señalarse, como semejanza, el que ambos introducen dicho género y aluden a sus categorías constitutivas. No obstante, en el señalamiento de tales categorías hay diferencias notorias, las cuales son explicables debido a que el programa de estudios no define qué criterio se debe seguir. Así, cada libro de texto se maneja con sustentos teóricos diferentes: el de Varela y Sandino adopta una posición más tradicional, en la que se observa, además, cierta confusión; en tanto que el de la serie "Hacia el siglo XXI" parece guiarse, además de por esos postulados tradicionales, por una posición crítica.

Por otra parte, el texto de la serie "Hacia el siglo XXI" presenta un desarrollo más completo de los contenidos programáticos, pues no solo plantea las categorías constitutivas del género, sino que dedica un buen espacio a la reflexión en torno a la convencionalidad del género.

Una última diferencia que interesa señalar tiene implicaciones didácticas. El libro $E s$ pañol $9^{9}$ año se manifiesta muy directivo al presentar las características del género: primero las expone en una forma bastante esquemática; y, luego del análisis de los ensayos, pide a los estudiantes que las relacionen con los textos leídos. Por el contrario, el libro de la serie "Hacia el siglo XXI" presenta cada uno de los ensayos, para que, una vez conocidos los textos, los alumnos puedan reflexionar acerca de las categorías distintivas del género, de modo que no las discute hasta tanto los estudiantes no hayan tenido una experiencia previa con textos representativos; en este proceder, puede observarse una posición más cercana a la construcción de conocimientos.

\subsubsection{En têrminos especificos}

En cuanto a la lectura que se hace de los ensayos "¿Qué hora es...?" y "La isla que somos", el libro de texto Español 9o año la plantea en función de ciertas ideas claves. Organiza esas ideas en grandes bloques según su significado. Véase un fragmento de la presentación de la segunda idea clave del ensayo "¿Qué hora es...?”:

\section{"2. Situación social de la mujer en Costa Rica.}

*El hogar la educa para que sea buena señora de casa, correcta esposa y fuerte madre.

'No sabe para qué estudia: van porque 'papá quiere', porque es bonito o por necesidad de obtener el bachiller. "Carece de orientación verdadera..." (Varela y Sandino, 1997, p. 279).

En cuanto a los elementos de análisis específicos que establece el programa del Ministerio de Educación Pública para los ensayos asignados, este libro de texto se apega estrictamente a ellos. Sin embargo, no los desarrolla, sino que los deja como ejercicios para los estudiantes.

Además, sigue el mismo esquema para ambos ensayos. Lo único que cambia es la actividad final, de producción textual, que en el caso de "¿Qué hora es...?" sí aparece ("Realizo una argumentación acerca del tema 'La identidad de la mujer', con base en el contenido del ensayo y la sociedad actual. Lo leo en clase", Varela y Sandino, 1997, p. 282), mientras que en "La isla que somos" no aparece.

El libro de la serie "Hacia el siglo XXI" también basa su lectura de los ensayos en la argumentación que en ellos se desarrolla. Así, plantea una idea básica, alrededor de la cual se exponen varios subtemas, con sus respectivos ejemplos. En el caso de "¿Qué hora es...?", la idea básica que se plantea es "La formación integral de la mujer como ser humano"; los subtemas son los siguientes: el tipo de mujer en que se inspira esta reflexión, una caracterización de las mujeres que viven 
frivolamente, y seis ideas en que se sustenta la formación integral de la mujer como ser humano. Véase el ejemplo:

\footnotetext{
“En qué consiste la formación integral de la mujer como ser humano que propone Yolanda Oreamuno?

* Es una educación cuyo norte es la independencia de criterio, tanto en el hogar como en la escuela y en la sociedad toda. Hay que empeñarse en crear una personalidad femenina libre de la tutela del varón.

No sabemos de nosotras mismas, sino to que el hombre nos ha enseñado..

Así, lo necesario es forjar la verdadera personalidad femenina...

(...)

* Es una educación que conecta los conocimientos con las necesidades y la vida diaria del ser humano.

Debe liquidarse ese concepto de la ciencia abstracta e inútil, englobándola, mediante similitudes o antagonismos, con los problemas diarios..."

(Viquez y otros, 1996, p. 226).
}

Respecto de los elementos específicos mencionados en el programa de estudios del Ministerio de Educación Pública (registros del habla, código apreciativo...), este libro no los desarrolla todos, sino que escoge dos: la relación del texto con el contexto social y la relación del texto con el género ensayístico.

La importancia conferida al contexto social se observa tanto en las ideas destacadas de cada ensayo como en los ejercicios y temas propuestos para la discusión, los cuales exigen contrastar lo que exponen los ensayos con la realidad que circunda a los estudiantes. Véanse, a manera de ilustración, las siguientes citas:

\footnotetext{
"¿Qué actualidad tienen las ideas de Yolanda Oreamuno? ¿Considera usted que, de 1938 a la fecha, ha habido cambios significativos en lo que aquí se plantea?" (Víquez y otros, 1996, p. 227).
}

\begin{abstract}
"Piensa usted que es cierto que nuestro país se ve a sí mismo como una isla, un espacio aislado de otras realidades? ¿Cree usted que los costarricenses por lo general carecen de solidaridad hacia el resto de América Latina?" (Víquez y otros, 1996, p. 230).
\end{abstract}

La relación entre los textos estudiados y el género se establece, en Español 9, a partir del carácter ideológico del ensayo. Ello se realiza en el último ejercicio de la unidad, en el que -tras plantear algunas reflexiones en torno al género- se pide al estudiante que relacione tal rasgo con los ensayos estudiados; obsérvese: "Reexamine los ensayos ‘Qué hora es...?' y 'La isla que somos', así como sus análisis respectivos, y trate de sintetizar cuáles son los marcos ideológicos desde los cuales están escritos." (Víquez y otros, 1996, p. 233).

Sobre este punto, puede señalarse una semejanza, la cual reside en que ambos libros de texto le confieren mucha importancia a las ideas planteadas en cada ensayo. Los elementos de análisis propuestos en el documento curricular aparecen en un segundo plano en la disposición de la unidad del libro Español 9a año, en el que se dejan como ejercicio para los estudiantes. Por su parte, en el libro de la serie "Hacia el siglo XXI", dichos elementos no se consideran en su totalidad, ya que se explotan únicamente las relaciones con el contexto y con el género literario.

\subsection{Orientación teórico-literaria}

Aunque los autores del libro Español $9^{\circ}$ año indican, en la "Presentación", que realizarán un estudio sociocrítico de los textos literarios, resulta bastante débil el señalamiento de la función ideológica de la literatura, así como el nexo de esta con el contexto sociocultural. El tratamiento que se da a los ensayos se orienta, más bien, hacia una lectura de las principales ideas expuestas y, en el caso de los ejercicios, es evidente una tendencia estructuralista, pues enfatiza en elementos tales como los registros del habla, el código apreciativo, las relaciones entre el emisor y el receptor. Además, el estudio de tales categorías se formula de igual manera para uno y otro texto, sin respetar sus diferencias particulares.

El libro de la serie "Hacia el siglo XXI", por el contrario, enfatiza en los aspectos sociocríticos, es decir, le interesa más destacar la función ideológica de la literatura y su relación con el contexto social. A su vez escoge, de entre los elementos de análisis que el programa oficial sugiere para cada ensayo, aquellos que le resulten más productivos para su 
lectura interpretativa, la cual enfatiza en lo ideológico.

En relación con este punto, son mayores las diferencias que las semejanzas entre ambos textos.

\section{Conclusiones}

5.1 En cuanto a la orientación didáctica, los libros de texto analizados se encuentran en posiciones diametralmente opuestas. Español 9a año emplea una metodología pasiva, la cual impone una pauta muy directiva. Por su parte, Español 9, de la serie "Hacia el siglo XXI", concuerda con la orientación del programa de estudios del Ministerio de Educación Pública, ya que la metodología empleada en este texto es activa, a la vez que se intenta promover un aprendizaje significativo, en que el componente motivacional juega un papel muy importante.

5.2 En términos generales, la orientación temática, es decir, respecto de aquellos temas relacionados con el género ensayístico propiamente tal, es diferente entre ambos libros de texto, sin que por ello dejen de apegarse, de alguna manera, al programa. Ante una falta de definición de criterios en el documento curricular, cada uno de los libros desarrolla las características del ensayo según un marco de referencia distinto, el cual, en el caso de Español 9a año, aparece confuso. En este punto, el de la serie "Hacia el siglo XXI" resulta más profundo, pues también lleva sus reflexiones al plano del género como función convencional del lenguaje.

5.3 En términos específicos, la orientación temática -en este caso, aquella que contempla los elementos de análisis específicos que establece el programa de estudios del Ministerio de Educación Pública para los ensayos asignados- es seguida más de cerca por el libro Español 9a año, el cual la contempla en los ejercicios para los estudiantes. En el libro de la serie "Hacia el siglo XXI" no se consideran todos los elementos, sino que el análisis se centra en aquellos que permitan explotar mejor las ideas desarrolladas en cada ensayo, otorgándole gran importancia al contexto social.

5.4 Por último, acerca de la orientación teórico-literaria, el libro Español $9^{\circ}$ año se acerca a una posición estructuralista, en tanto que el de la serie "Hacia el siglo XXI" enfatiza en los aspectos sociocríticos, es decir, le interesa más destacar la función ideológica de la literatura y su relación con el contexto social.

5.5 En suma, está claro que de un mismo documento curricular pueden desprenderse desarrollos diferentes en el nivel de los libros de texto. No obstante, resulta extremadamente difícil establecer -en términos absolutos- la mayor o menor relación entre los libros de texto y el documento que les sirve de base. Lo anterior se explica por el hecho de que tal "desarrollo" no constituye una labor mecánica, sino que responde a un trabajo de lectura e interpretación de las directrices programáticas. En dicho proceso - como en toda actividad lectora- el sujeto -en este caso, los autores- realizan una labor de "selección" de aquellos asuntos que consideran más importantes desde su punto de vista. Y, tratándose de los estudios literarios, esos puntos de vista o marcos de referencia suelen ser diversos $\mathrm{y}$, en no pocos casos, contrastantes.

\section{Referencias bibliográficas}

Amoretti H., María. Diccionario de términos asociados en teoría literaria. San José: EUCR, 1992.

Costa Rica, Ministerio de Educación Pública. "Español: III Ciclo", San José: El Ministerio, 1995.

Dimaté Rodríguez, Cecilia. Módulo Introductorio. Algunos conceptos básicos sobre el texto escolar. Elaborado por la Oficina de Educación de la UNESCO para Centroamérica y Panamá en convenio con el CERLALC, en el marco del Proyecto UNESCO / ALEMANIA 507 / 
RLA / 11 "Elaboración de textos y materiales de lectura para la educación básica en el Istmo Centroamericano", 1994.

Murillo Hernández, German. "Comentario del ensayo 'QQué hora es?' de Yolanda Oreamuno", 1996. Tomado de: Kiosco de Información, http: //www.mep.go.cr/paqueteshtm/espa\%flol/ciclo3/a109618.e09.htm

Todorov, Tzvetan. Poética. ¿Qué es el estructuralismo? Buenos Aires: Losada, 1975.

Varela, Marubeni y Sandino, Wálter. Español 9o año, Heredia: Ediciones Marwal, 1997.

Víquez Jiménez, Alí; Rojas Blanco, Lilliam; Rojas Porras, Marta. Español 9: texto, San José: EUCR, 1996.

\section{Anexo}

\section{Guía de análisis del desarrollo del programa de estudios de español de noveno año del Ministerio de Educación Pública de Costa Rica en dos libros de texto}

\section{Sobre la orientación didáctica:}

- La metodología empleada, ¿es activa?, ¿o es pasiva?

\section{Respecto de la orientación temática:}

\section{En términos generales:}

- ¿Se presenta la literatura como una práctica social, como una forma ideológica y como una institución?
- ¿Se contempla el género ensayístico como una función convencional del lenguaje y como una forma de relación particular con el mundo, que sirve de regulación o de expectativa para guiar al lector en el encuentro con el texto?

- ¿Se fortalece la comprensión del género al ampliar los géneros literarios estudiados en niveles anteriores (épica, lírica y drama)?

- ¿Se presenta el predominio de las diversas categorias constitutivas en cada uno de los géneros, con el fin de obtener una visión global de las regulaciones que han orientado la lectura y la escritura de lo literario?

\section{En términos específicos (con base} en cada uno de los ensayos estudiados):

- ¿Se analizan los registros del habla?

- ¿Se estudia la función del hablante en primera persona como recurso coloquial?

- ¿Se aborda el código apreciativo?

- ¿Se analizan las relaciones entre el emisor y el receptor?

- ¿Se estudian las relaciones de cada uno de los ensayos con el contexto sociocultural y con el género literario?

\section{Acerca de la orientación teórico-literaria:}

- ¿A qué se le da más importancia: a la función ideológica de la literatura y su relación con el contexto social (a los postulados de la sociocrítica), o al análisis de elementos específicos similares en ambos ensayos (tendencia estructuralista)? 